\title{
A Novel Antigen Sensitive to Calcium Chelation That is Associated with the Tip Links and Kinocilial Links of Sensory Hair Bundles
}

\author{
Richard J. Goodyear and Guy P. Richardson \\ School of Biological Sciences, University of Sussex, Falmer, Brighton, BN1 9QG, United Kingdom
}

\begin{abstract}
Tip links are extracellular, cell-surface-associated filaments of unknown molecular composition that are thought to gate the mechanotransducer channel of the sensory hair cell. They disappear from the hair bundle in response to calcium chelation and lanthanum treatment and resist degradation by the protease subtilisin. A monoclonal antibody derived from a hybridoma screen identified a novel antigen associated with tip links, the tip-link antigen. The tip-link antigen is also associated with kinocilial links, subtilisin-resistant filaments that are sensitive to calcium chelation and connect the kinocilium to the tallest stereocilia of the hair bundle. Furthermore, the tip-link antigen is expressed in the retina, where it is associated with the ciliary calyx, a ring of microvilli that surrounds the outer segment of the photoreceptor. The tip-link antigen rapidly disappears from the surface of the hair bundle in response to calcium chelation. It is also subtilisin resistant, relative to the ankle-link antigen, an antigen associated with another type of hair bundle link. The tip-link antigen is lanthanum sensitive and, like tip links, reappears on the surface of the hair bundle after calcium chelation. The monoclonal antibody to the tip-link antigen immunoprecipitates two concanavalin A-reactive polypeptides with apparent molecular masses of 200 and $250 \mathrm{kDa}$ from detergent extracts of the retina. These results provide the first identification of a cell surface antigen associated with tip links, indicate that tip links share properties in common with kinocilial links, and reveal a second epitope that, along with the ankle-link antigen, is common to both sensory hair bundles and the ciliary calyx of photoreceptors.
\end{abstract}

Key words: hair cell; mechanotransduction; stereocilia; tip link; retina; ciliary calyx; photoreceptor

\section{Introduction}

Hair cells are mechanosensory cells found in the inner ears and lateral line organs of vertebrates. They are polarized epithelial cells with a hair bundle that projects from their apical end. The hair bundle is the site of mechanotransduction. It is composed of stereocilia, modified microvilli that are arranged on the cell surface in rows of increasing height. In most types of hair cell, a single kinocilium lies adjacent to the tallest row of stereocilia. A number of cell surface specializations, or link types, that are associated with sensory hair bundles have been described previously (Pickles et al., 1984; Furness and Hackney, 1985; Csukas et al., 1987; Jacobs and Hudspeth, 1990; Nagel et al., 1991; Goodyear and Richardson, 1992, 1999). In the auditory organ of the chick inner ear, the basilar papilla, four morphologically distinct link types can be distinguished between stereocilia (Goodyear and Richardson, 1992). Working from the top of the hair bundle down, there are tip links, horizontal top connectors, shaft connectors, and finally, ankle links (Goodyear and Richardson, 1992). These link types can be distinguished by their relative sensitivities to treatment with calcium chelators and the protease subtilisin (Goodyear and Richardson, 1999). The tip link is a fine filament that extends obliquely from the tip of a stereocilium and contacts the

Received Nov. 25, 2002; revised March 27, 2003; accepted March 28, 2003.

This work was supported by The Wellcome Trust Grant 057410/Z/99Z. We thank lan Russell and Kevin Legan for their helpful comments on this manuscript.

Correspondence should be addressed to Dr. Guy P. Richardson, School of Biological Sciences, University of Sussex, Falmer, Brighton, BN1 90G, UK. E-mail: g.p.richardson@sussex.ac.uk.

Copyright $\odot 2003$ Society for Neuroscience $\quad 0270-6474 / 03 / 234878-10 \$ 15.00 / 0$ side of an adjacent stereocilium (Pickles et al., 1984; Furness and Hackney, 1985). It is lost from the cell surface after exposure to either BAPTA or lanthanum and resists degradation by the protease subtilisin (Jacobs and Hudspeth 1990; Assad et al., 1991; Goodyear and Richardson, 1999; Kachar et al., 2000). The available evidence indicates that the tip link may gate the mechanotransducer channel (Assad et al., 1991; Zhao et al., 1996). Thus far, surprisingly little is known about the molecular composition of the different interstereocilial link types. Monoclonal antibodies (mAbs) that recognize components of the shaft connectors and the ankle links have been generated previously (Richardson et al., 1990; Goodyear and Richardson, 1992, 1999), and the 275 kDa hair-cell antigen (HCA) (Richardson et al., 1990), a component of the shaft connectors (Goodyear and Richardson, 1992), has been recently identified (Legan et al., 2001) as a receptor-like protein tyrosine phosphatase, now known as protein tyrosine phosphatase receptor Q. In this study, we describe the tip-link antigen (TLA), a novel antigen that is associated with both tip links and a class of link that connects the kinocilium to adjacent stereocilia.

\section{Materials and Methods}

Production of monoclonal antibodies. Vestibular organs (utricular and saccular maculae and ampullary cristae) were obtained from the inner ears of early posthatch chicks by dissection in PBS (in mM: $150 \mathrm{NaCl}$ and 10 sodium phosphate, $\mathrm{pH} 7.2$ ) containing a mixture of protease inhibitors [ $2 \mathrm{~mm}$ benzamidine, $1 \mu \mathrm{g} / \mathrm{ml}$ leupeptin, $10 \mu \mathrm{g} / \mathrm{ml}$ pepstatin, and 0.1 mM phenylmethylsulfonyl fluoride (PMSF)]. Tissues were collected in ice-cold PBS, and, after each dissection session, they were frozen and stored in liquid $\mathrm{N}_{2}$ until use. Pooled frozen tissue samples (from $\sim 250$ 
inner ears) were thawed in cold PBS containing the same mixture of protease inhibitors used for dissection with the concentrations of leupeptin and PMSF raised to $10 \mu \mathrm{g} / \mathrm{ml}$ and $1.0 \mathrm{~mm}$, respectively. After homogenization in a tight-fitting, handheld Teflon-glass homogenizer, a crude membrane fraction depleted of otoconia, extracellular matrix, and soluble cytoplasmic proteins was prepared by differential centrifugation in a refrigerated Eppendorf Scientific (Hamburg, Germany) 5415 benchtop centrifuge. The resulting tissue pellet was finally washed twice in PBS without protease inhibitors, resuspended in $1 \mathrm{ml}$ of PBS, and used to immunize a $\mathrm{BALB} / \mathrm{c}$ mouse. The mouse was injected intraperitoneally initially three times at 1 month intervals, rested for 12 months, boosted twice with an interval of 1 month between each injection, and used for the preparation of monoclonal antibodies $7 \mathrm{~d}$ after the final boost. A membrane fraction prepared from $\sim 250$ ears was used for each injection. Animal procedures were performed in accordance with United Kingdom Home Office regulations. Hybridomas (Köhler and Milstein, 1975) were prepared according to standard procedures, using NS1 mouse myeloma cells and spleen cells at a ratio of $\sim 1: 10$ and polyethylene glycol for the fusion. Fused cells were plated into the wells of eight 48 -well plates, with a $1 \mathrm{ml}$ volume of hypoxanthine-aminopterin-thymidine growth medium containing $10 \%$ Doma Drive (Immune Systems, Paignton, UK) in each well, and grown at $37^{\circ} \mathrm{C}$ in an atmosphere of $94 \%$ air- $6 \% \mathrm{CO}_{2}$. After $10 \mathrm{~d}$ growth, most wells contained multiple clones. The medium from each well was sampled and assayed for hair cell-reactive antibodies by immunofluorescence microscopy on cryosections of aldehyde-fixed inner ear tissues (see below), using two layers of fluorochrome-conjugated antibodies to increase signal detection levels. Cells secreting antibodies that stained the tips of hair bundles were cloned by limiting dilution on three successive occasions to obtain G19, a monoclonal hybridoma cell line that secretes an IgG1 antibody against a hair cell surface antigen referred to as the TLA.

Immunofluorescence microscopy. Tissues were fixed in $3.7 \%$ formaldehyde $-0.025 \%$ glutaraldehyde in $0.1 \mathrm{~m}$ sodium phosphate buffer, $\mathrm{pH}$ 7.4, for $1 \mathrm{hr}$ at room temperature and washed three times in PBS. For cryosectioning, tissues were equilibrated in $30 \%$ sucrose in PBS and embedded in $1 \%$ low gelling temperature agarose (type VII; Sigma, Poole, UK) in PBS containing $18 \%$ sucrose. The agarose blocks containing the tissue samples were frozen onto cryotome chucks with Cryospray (Bright Instrument, Huntingdon, UK), and sections of $10 \mu \mathrm{m}$ thickness were cut at a temperature of $-30^{\circ} \mathrm{C}$. Sections were mounted on gelatin-coated glass microscope slides. Cryosections and tissue whole mounts were preblocked with Tris-buffered saline (in mM: $150 \mathrm{NaCl}$ and 10 Tris- $\mathrm{HCl}$, pH 7.4) containing $10 \%$ horse serum (TBS/HS) for $1 \mathrm{hr}$, stained overnight with monoclonal antibodies diluted in TBS/HS, and washed three times with TBS. To detect bound primary antibodies, samples were stained with FITCconjugated rabbit anti-mouse Ig, followed by FITC-conjugated swine antirabbit Ig, both at a dilution of 1:100 in TBS/HS. After a final wash, samples were mounted in Vectashield (Vector Laboratories, Peterborough, UK).

For double labeling, isotype-specific antibodies were used to detect the bound primary antibody, and appropriate fluorochrome-labeled antibodies were applied at the third step of the labeling procedure. In addition to $\mathrm{mAb} \mathrm{G} 19$, the following mAbs of specified isotype were used in this study: mAb D10, IgG1; mAb H28, IgG2a; mAb H27, IgG2a; mAb F44, IgG2a; and mAb E40, IgG1. mAbs D10 and H27 recognize the HCA, whereas mAbs $\mathrm{H} 28, \mathrm{E} 40$, and F44 recognize the ankle-link antigen (ALA).

Immunogold electron microscopy. Tissues were dissected, fixed as described above, preblocked in TBS/HS, and incubated overnight in $\mathrm{mAb}$ G19 supernatant diluted 1:100 in TBS/HS. Controls were incubated in $\mathrm{mAb}$ E40, an IgG1 mAb of the same isotype as mAb G19 that recognizes ankle links. Tissue pieces were washed extensively with TBS, incubated overnight in an unconjugated linker antibody, rabbit anti-mouse IgG1, at a dilution of 1:100 in TBS/HS, washed extensively with TBS, and incubated in $5 \mathrm{~nm}$ colloidal gold-conjugated goat anti-rabbit IgG (British BioCell International, Cardiff, UK) at a dilution of 1:10 in TBS/HS containing 1 mm EDTA, $0.05 \%$ Tween 20 , and 1 mm sodium azide for $48-72$ $\mathrm{hr}$. Antibody incubation steps were performed at $4^{\circ} \mathrm{C}$ on a rotator. After gold labeling, tissue pieces were washed five times with TBS/HS containing $0.05 \%$ Tween 20 and $1 \mathrm{~mm}$ sodium azide, five times with PBS, refixed in $2.5 \%$ glutaraldehyde in $0.1 \mathrm{~m}$ sodium cacodylate, $\mathrm{pH} 7.2$, for $1 \mathrm{hr}$, washed three times with cacodylate buffer, and fixed with $1 \%$ osmium tetroxide for $1 \mathrm{hr}$. In some labeling experiments, refixation was performed using fixatives containing $0.5 \%$ ruthenium red to improve the contrast of cell surface-associated material. Tissue pieces were finally washed three times in cacodylate buffer and twice with $\mathrm{H}_{2} \mathrm{O}$, dehydrated through a series of ascending concentrations of ethanol, equilibrated in propylene oxide, and embedded in Taab 812 resin. Tissue blocks were cured at $60^{\circ} \mathrm{C}$ for $24-48 \mathrm{hr}$. Ultrathin sections (100 and $200 \mathrm{~nm}$ thick) were cut on a Reichert Ultracut E microtome (Leica, Milton Keynts, UK), mounted on copper grids, counterstained with $1 \%$ aqueous uranyl acetate followed by lead citrate, and viewed in a Hitachi (Tokyo, Japan) 7100 transmission electron microscope operating at $75 \mathrm{kV}$.

BAPTA, lanthanum, and subtilisin treatment. Subtilisin (protease type $\mathrm{XIV}$; Sigma) was prepared as a stock solution at $5 \mathrm{mg} / \mathrm{ml}$ and diluted to a concentration of $50 \mu \mathrm{g} / \mathrm{ml}$ in HEPES-buffered (10 mM; pH 7.2) HBSS (HBHBSS) just before use. HBHBSS with 5 mm BAPTA was prepared from $10 \times$ concentrated $\mathrm{Ca} / \mathrm{Mg}$-free HBSS, adding $100 \times$ concentrated $\mathrm{MgCl}_{2} / \mathrm{MgSO}_{4}, 50 \mathrm{~mm}$ BAPTA, and $1 \mathrm{M}$ HEPES to final concentrations of $1.2 \mathrm{~mm} \mathrm{Mg}^{2+}, 5 \mathrm{~mm}$, BAPTA, and $10 \mathrm{~mm}$ HEPES, and adjusting the $\mathrm{pH}$ to 7.2. Tissue pieces (utricular maculae and basilar papillae) sufficient for one experiment (usually $20-30$ organs) were collected within a period of $<1 \mathrm{hr}$ and stored on ice in HBHBSS until use. For experiments using BAPTA and lanthanum, the otoconial membranes and all of the adherent otoconia were removed before treatment. The effects of subtilisin were examined in the presence and absence of the otoconial membrane and its associated otoconia. The effects of lanthanum were tested using a saline solution containing the following (in mM): $155 \mathrm{NaCl}, 6 \mathrm{KCl}, 3 \mathrm{D}$-glucose, 10 HEPES, pH 7.2, $4 \mathrm{CaCl}_{2}$, and $5 \mathrm{LaCl}_{3}$, as described by Kachar et al. (2000). Experiments with subtilisin and lanthanum were performed at room temperature $\left(20-24^{\circ} \mathrm{C}\right)$. Experiments with BAPTA were performed at room temperature or in a cold room $\left(3^{\circ} \mathrm{C}\right)$. Tissues were transferred between solutions ( $3 \mathrm{ml}$ volumes in $35-\mathrm{mm}$-diameter plastic Petri dishes) under microscopic control using fine forceps. Treatments were terminated by plunging the tissues into fixative appropriate for immunofluorescence microscopy (see above) or transmission electron microscopy (see below).

To examine the recovery of antigen after BAPTA treatment, all of the
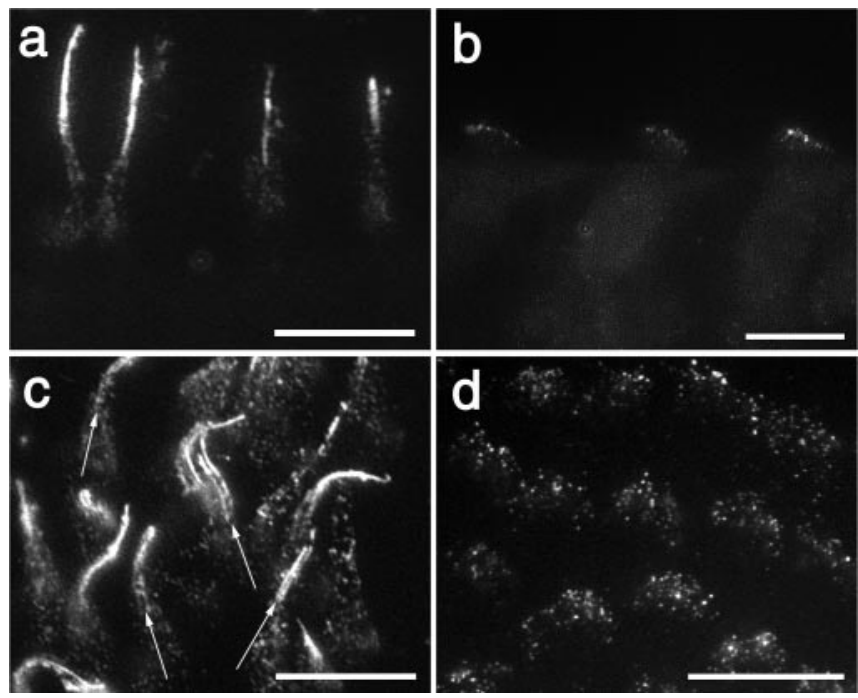

Figure 1. Immunofluorescence labeling of hair bundles in the chick inner ear with $\mathrm{mAb} G 19$. Sections $(a, b)$ and whole mounts $(c, d)$ of the extrastriolar region of the utricular macular $(a, c)$ and basilar papilla $(b, d)$ were labeled with $\mathrm{mAb} G 19$, followed by two layers of FITC-conjugated anti-antibodies and photographed with a $100 \times$ oil immersion lens (numerical aperture, 1.4) using a conventional light microscope. In the macula $(a, c)$, bright puncta are distributed over the surface of the hair bundle, and the distal end of the bundle is brightly stained over a considerable length. This distal staining sometimes resolves into two fine, closely separated, parallel lines (c, arrows). In the basilar papilla $(b, d)$, punctate staining is observed toward the distal end of each hair bundle. Scale bars, $10 \mu \mathrm{m}$. 

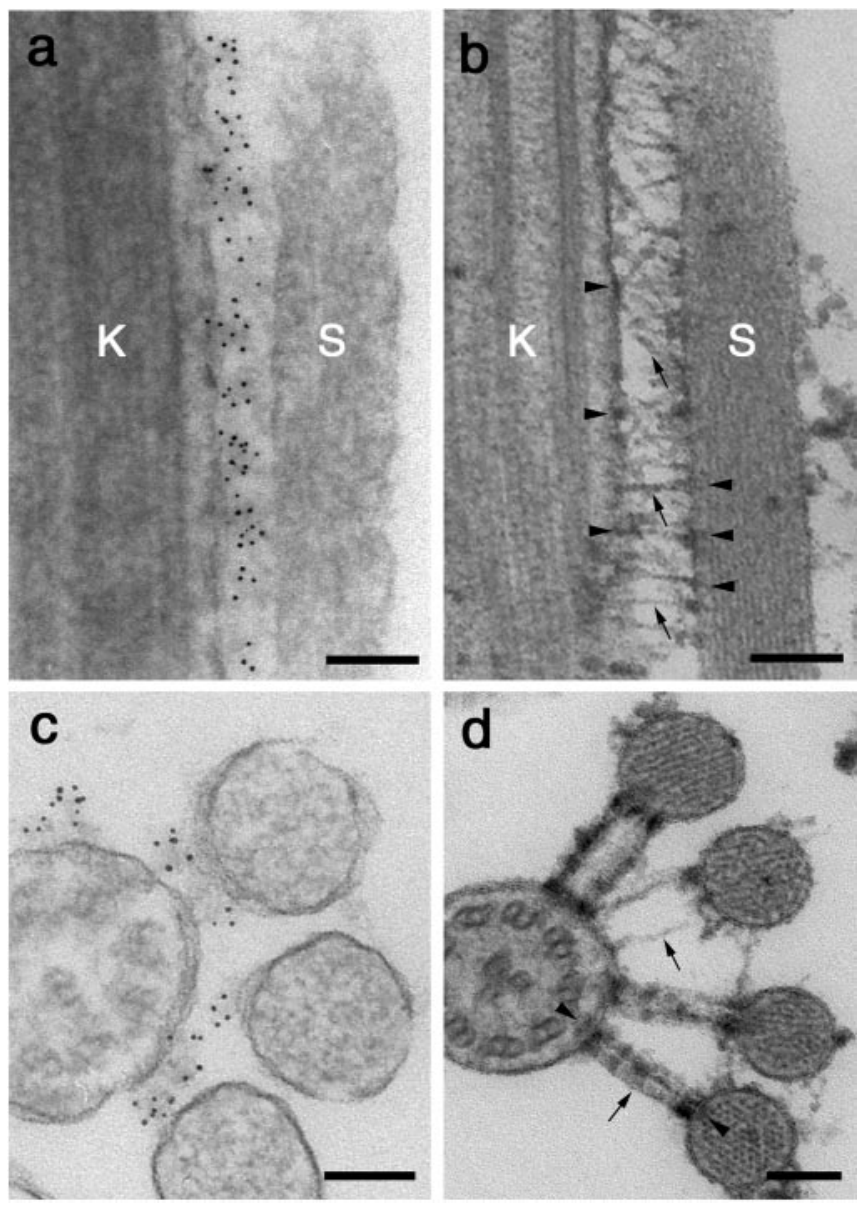

Figure 2. Immunogold electron microscopic localization of the mAb G19 epitope and ultrastructure of the kinocilial links. Transmission electron micrographs showing longitudinal $(a, b)$ and horizontal $(c, d)$ sections of immunogold-labeled $(a, c)$ and tannic acid-contrasted $(b, d)$ macular hair bundles. The $G 19$ epitope localizes to the gap between the kinocilium and the taller stereocilia $(a, c)$ and is associated with dense staining material. In conventionally fixed, tannic acid-contrasted preparations, numerous fine filaments (arrows) are seen spanning the gap between the kinocilium and the taller stereocilia $(b, d)$. $d$, Top arrow, A single link; bottom arrow, laterally aggregated links. Membrane density is often enhanced at the attachment sites of these filaments (arrowheads, $b, d$ ) on both the intracellular and extracellular faces of the membrane. K, Kinocilium; $S$, stereocilium. Scale bars: $a-d, 100 \mathrm{~nm}$.

procedures were performed under sterile conditions without the use of potentially ototoxic antibiotics. After treatment with $5 \mathrm{~mm}$ BAPTA for 2 min at room temperature, maculae were washed three times in HBHBSS and then incubated in 90\% DMEM with Earle's salts-10\% fetal calf serum at $37^{\circ} \mathrm{C}$ in a $94 \%$ air $-6 \% \mathrm{CO}_{2}$ atmosphere for 1 or $20 \mathrm{hr}$ before fixation.

All of the experiments described in this section were performed using a minimum of three maculae on each occasion for each experimental condition. Experiments analyzed by immunofluorescence microscopy were replicated on at least three separate occasions. Experiments analyzed by electron microscopy were replicated on at least two separate occasions.

Transmission electron microscopy. Inner-ear tissues were fixed in $2.5 \%$ glutaraldehyde in $0.1 \mathrm{~m}$ sodium cacodylate buffer, $\mathrm{pH} 7.2$, containing $1 \%$ tannic acid for $2 \mathrm{hr}$ at room temperature, rinsed three times in sodium cacodylate buffer, postfixed with cacodylate-buffered $1 \%$ osmium tetroxide for $1 \mathrm{hr}$, and rinsed three times in cacodylate buffer. Tissue were then dehydrated and embedded as described above for immunogold electron microscopy.

Immunoprecipitations. Retinas were dissected from chick eyes in TBS containing $1 \mathrm{~mm} \mathrm{CaCl}_{2}(\mathrm{TBS} / \mathrm{Ca})$ and the same mixture of protease inhibitors used for the collection of inner-ear tissues for immunization,
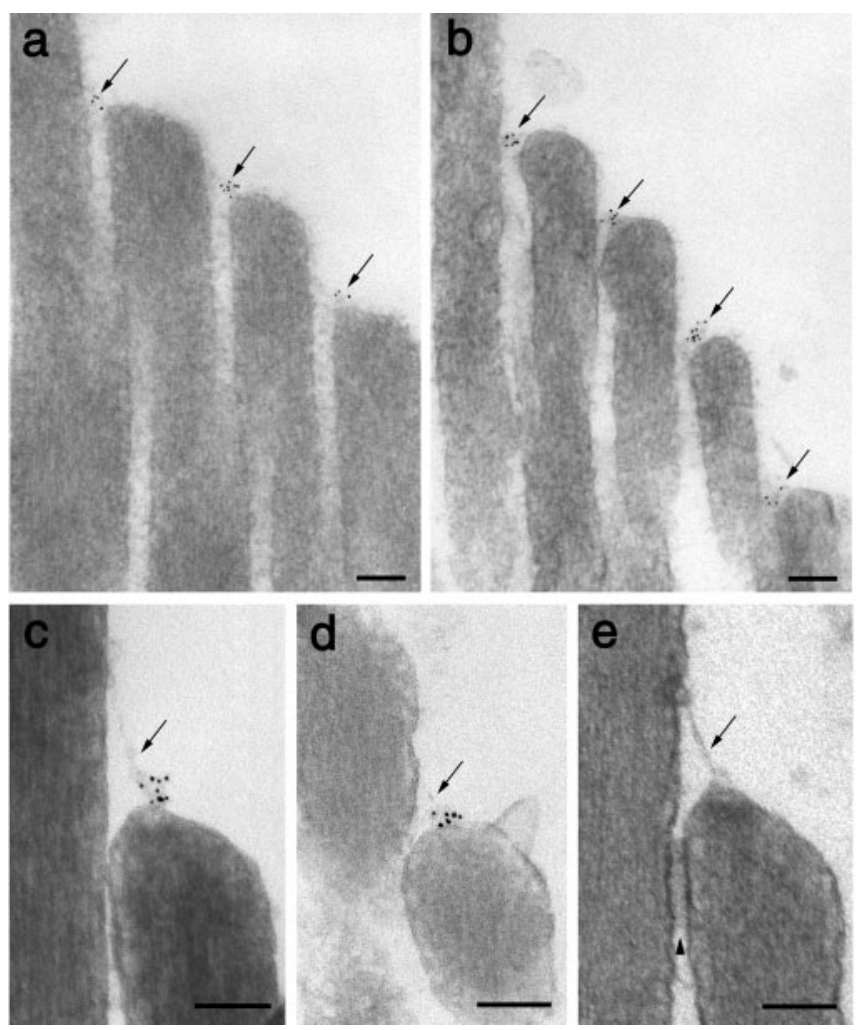

Figure 3. TLA distribution at tip-link sites on different types of hair bundle. $a-d$, Transmission electron micrographs illustrating examples of hair bundles from the striolar $(a)$ and extrastriolar $(b)$ regions of the utricle and the basilar papilla $(c, d)$ that have been immunogold labeled with mAb G19. Immunogold labeling (arrows) is observed between the tips of stereocilia and the sides of their adjacent taller stereocilia $(a-d)$. In some instances $(c, d)$, a tip link can be resolved at these sites. $e$, An example of a tip link (arrow) in a conventionally fixed, tannic acid-contrasted preparation from the striolar region of the utricular macula. A horizontal top connector can be seen just below the tip link (arrowhead). Scale bars, $100 \mathrm{~nm}$.

collected in ice-cold TBS/Ca, with the concentrations of leupeptin and PMSF raised to $10 \mu \mathrm{g} / \mathrm{ml}$ and $1.0 \mathrm{~mm}$, respectively, frozen, and stored at $-80^{\circ} \mathrm{C}$ until use. To prepare extracts, frozen retinas (from $\sim 60$ eyes) were thawed and homogenized in $10 \mathrm{ml}$ of cold TBS/Ca containing 1\% Triton X-100 (TX-100) and protease inhibitors, left to sit on ice for 15 $\mathrm{min}$, and centrifuged at $40,000 \times g_{\max }$ for $10 \mathrm{~min}$. The soluble supernatant was collected and recentrifuged at low speed $\left(3000 \times g_{\text {av }}\right.$ for $\left.10 \mathrm{~min}\right)$ to remove any flocculent material not pelleting firmly at the first centrifugation step. Aliquots of the supernatant were incubated with monoclonal antibodies overnight at $4^{\circ} \mathrm{C}$, and the immune complexes were collected on protein $\mathrm{G}$-agarose beads. After extensive washing with TBS/Ca containing $0.1 \% \mathrm{TX}-100$, the beads were heated in $2 \times$ concentrated SDS-PAGE sample buffer at $98^{\circ} \mathrm{C}$ for $4 \mathrm{~min}$, cooled to room temperature, and centrifuged for $1 \mathrm{~min}$ at $13,000 \times g_{\max }$. The eluted samples were run on $6 \%$ polyacrylamide gels, and the proteins were transferred to a polyvinylidene difluoride membrane using semidry electroblotting. Blots were preblocked with TBS- $0.1 \%$ Tween $20-3 \%$ BSA, incubated overnight in $5 \mu \mathrm{g} / \mathrm{ml}$ biotinylated concanavalin A (Vector Laboratories), washed with TBS- $0.1 \%$ Tween 20 , incubated for $1 \mathrm{hr}$ in $1 \mu \mathrm{g} / \mathrm{ml}$ alkaline phosphatase-conjugated streptavidin (Vector Laboratories), washed in TBS- $0.1 \%$ Tween 20 , washed in alkaline phosphatase buffer $(0.1 \mathrm{M}$ Tris$\mathrm{HCl}, \mathrm{pH} 9.5,150 \mathrm{~mm} \mathrm{NaCl}$, and $50 \mathrm{~mm} \mathrm{MgCl}_{2}$ ), and reacted in nitroblue tetrazolium/5-bromo-4-chloro-3-indolyl phosphate. To examine the sensitivity of the antigens to calcium chelation, frozen retinas were thawed and homogenized in TBS/Ca. The homogenate was divided into two equal aliquots, and EGTA was added to a final concentration of $5 \mathrm{~mm}$ to one of the aliquots. Both aliquots were incubated for $15 \mathrm{~min}$ at room temperature and returned to ice, and TX-100 was added to a concentration of $1 \%$. Soluble supernatants and immunoprecipitates were prepared 

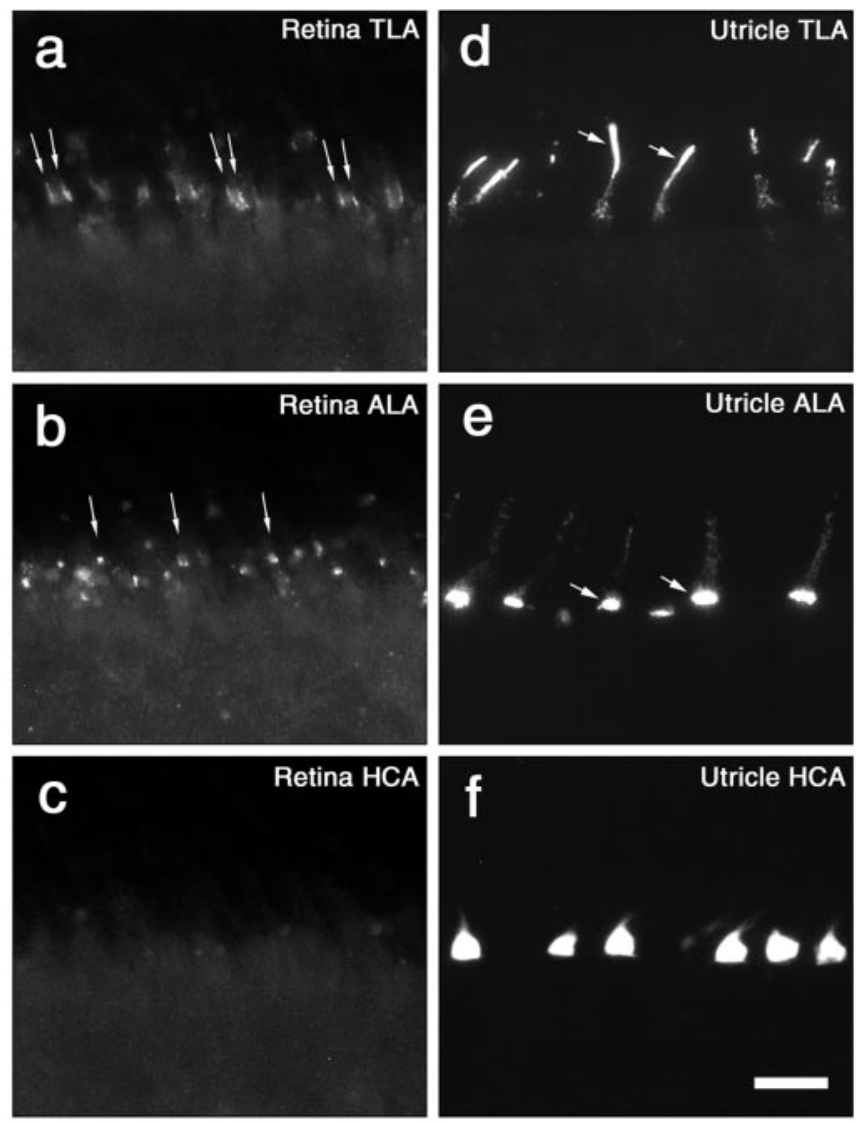

Figure 4. TLA, ALA, and HCA distribution in the retina and the utricular macula. Immunofluorescence micrographs comparing the distribution of the $\operatorname{TLA}(a, d)$, the ALA $(b, e)$, and the HCA $(c, f)$ in the retina $(a-c)$ and the extrastriolar region of the utricular macula $(d-f) . a$, The TLA (arrows) is distributed along the microvilli of the ciliary calyx that lie next to the proximal region of the photoreceptor outer segment. $b$, The ALA (arrows) is located at the base of the ciliary calyx. c, The HCA cannot be detected in the retina. $d$, The TLA (arrows) is concentrated at the tip of the hair bundle.e, The ALA is mostly localized around the base of the hair bundle (arrows). $f$ The HCA is distributed over the entire surface of the hair bundle. Scale bar: (in $f$ ) $a-f, 20 \mu \mathrm{m}$.

as described above, except that the protein G-agarose bead wash buffer for the samples prepared and precipitated in the presence of $5 \mathrm{~mm}$ EGTA contained $1 \mathrm{~mm}$ EGTA instead of $1 \mathrm{mM} \mathrm{CaCl}_{2}$.

\section{Results}

Immunofluorescence microscopy of cryosections (Fig. 1a,b) and whole mounts $(c, d)$ of the sensory epithelia of the chick inner ear reveals that the epitope recognized by $\mathrm{mAb}$ G19 is concentrated at the tip of the hair bundle. With vestibular hair cells, the most intense staining is associated with the distal one-half of the hair bundle, but bright spots of staining that appear to be associated with the tip of each stereocilium are also observed (Fig. 1a,c). With hair cells in the basilar papilla, the brightest staining is seen toward the distal end of the hair bundle (Fig. $1 b, d$ ). Experiments in which live maculae were labeled with mAb G19 before fixation indicate that the epitope is located on the extracellular surface of the hair bundle (data not shown).

Pre-embedding immunogold labeling and a comparison of the observed labeling pattern with the distribution of ultrastructural features on the surface of the hair bundle (Figs. 2, 3) reveal that the epitope recognized by G19 is associated with kinocilial links, links that connect the kinocilium to the tallest stereocilia in the vestibular hair cells (Fig. 2). The epitope is also found at the sites in which tip links are located on both vestibular and auditory
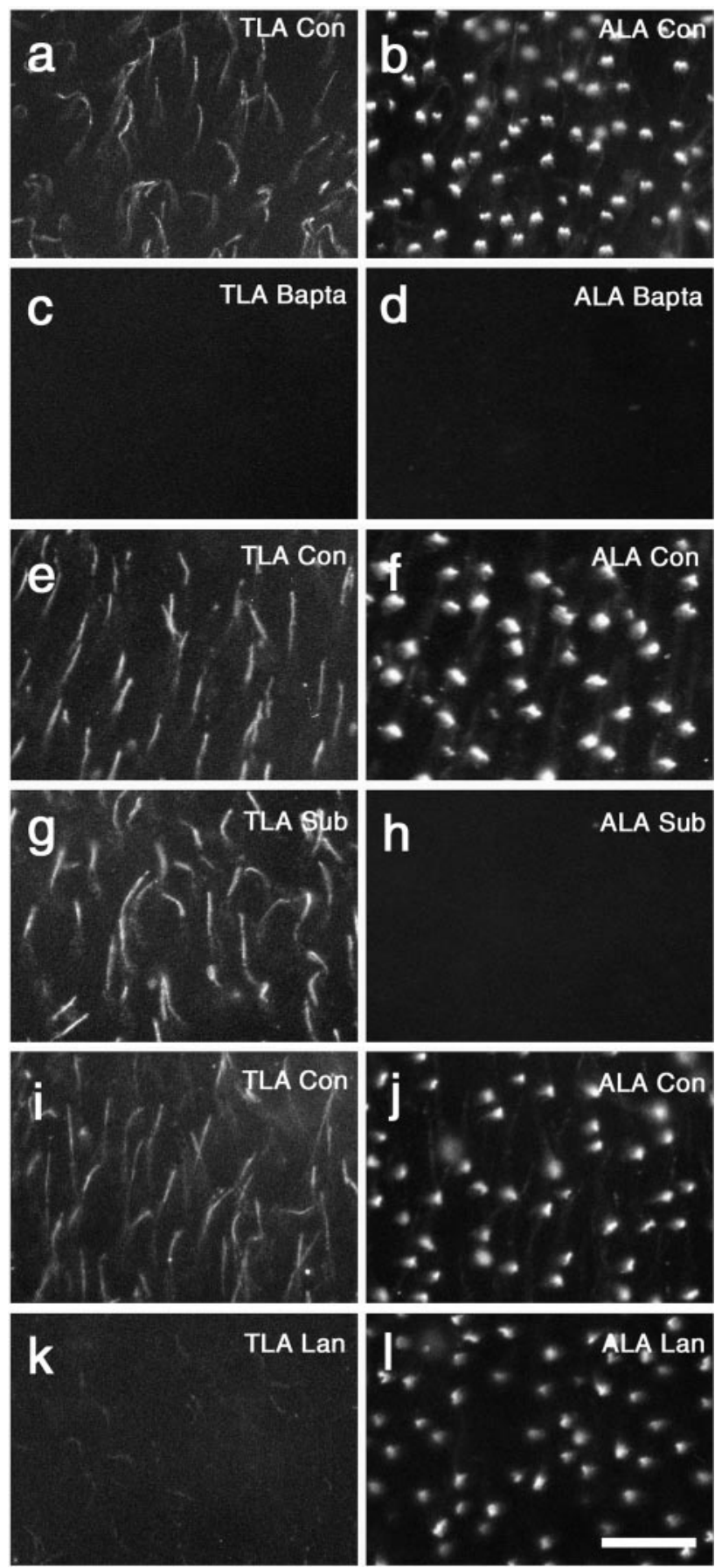

Figure 5. Relative sensitivities of the TLA and ALA to treatment with BAPTA, subtilisin (Sub), and lanthanum (Lan). Immunofluorescence micrographs of whole-mount preparations from saline-treated control (Con) maculae $(a, b, e, f, i, j)$, and maculae that were treated with $5 \mathrm{~mm}$ BAPTA for $15 \mathrm{~min}(c, d), 50 \mu \mathrm{g} / \mathrm{ml}$ subtilisin for $15 \mathrm{~min}(g, h)$, or $5 \mathrm{~mm}$ lanthanum for $10 \mathrm{~min}(k$, I) before fixation and staining for the TLA $(a, c, e, g, i, k)$ or the ALA $(b, d, f, h, j, I)$. BAPTA and lanthanum treatments were performed with maculae from which the otoconial membranes had been removed; subtilisin treatment was performed in the presence of an otoconial membrane. $a-d$, The TLA and the ALA are both BAPTA sensitive. $e-h$, The TLA is insensitive to subtilisin treatment relative to the ALA. $i-I$, The TLA is lanthanum sensitive, whereas the ALA is lanthanum insensitive. Scale bar: (in $/$ ) $a-I, 20 \mu \mathrm{m}$.

hair cells (Fig. 3). In preparations that have been fixed for conventional electron microscopy in the presence of tannic acid rather than lightly fixed for optimal preservation of antigenicity, individual kinocilial links appear as fine strands that are $4-5 \mathrm{~nm}$ 

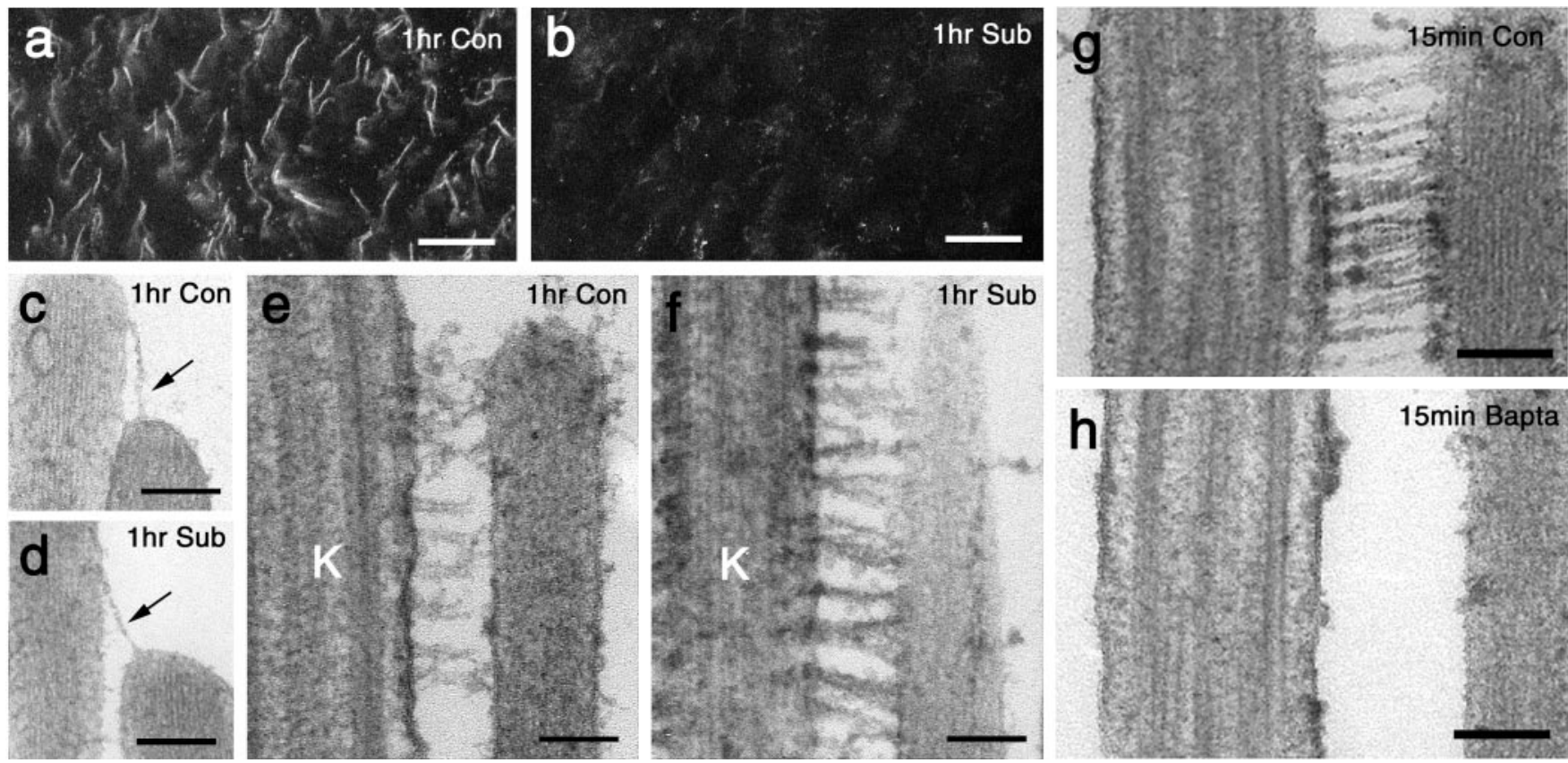

Figure 6. Effects of subtilisin and BAPTA. Immunofluorescence micrographs $(a, b)$ and transmission electron micrographs ( $c-h)$ of hair bundles from control (Con), saline-treated maculae ( $a$, $c$, $e, g)$, maculae treated with $50 \mu \mathrm{g} / \mathrm{ml}$ subtilisin (Sub) for $1 \mathrm{hr}$ at room temperature $(b, d, f)$, and maculae treated with 5 mm BAPTA for 15 min at room temperature ( $h$ ). All of the treatments were performed on maculae from which the otoconial membrane had been removed. The TLA is mostly lost from the cell surface after prolonged subtilisin exposure in the absence of an otoconial membrane $(a, b)$, whereas tip links $(c, d)$ and kinocilial links $(e, f)$ both resist such treatment. Kinocilial links are lost after exposure to BAPTA ( $g, h)$. Scales bars: $a, b, 10 \mu m ; c-h, 100 \mathrm{~nm}$.

in diameter (Fig. 2b,d). Their length varies along the extent of a single kinocilium, and they can be up to $180 \mathrm{~nm}$ long (Fig. $2 b, d$ ). Densities are often found on both the extracellular and the intracellular faces of the plasma membranes at the sites at which these kinocilial links attach to both the kinocilium and the stereocilium (Fig. 2b,d), although the intracellular densities are more frequently observed within the kinocilium. Gold particles are seen at tip-link sites on hair cells in the striolar (Fig. $3 a$ ) and extrastriolar (b) regions of the maculae and in the basilar papilla $(c, d)$. In some instances, a tip link can be resolved at these sites, despite the fixation and contrasting conditions being suboptimal for the visualization of these structures. In these cases, the gold particles generally appeared to be associated with the lower end of the tip link. The number of gold particles observed at each tip-link site varies from 3 to 10. An unconjugated linker antibody was used to amplify the signal during the labeling procedure, so the number of gold particles does not reflect antigen copy number present at each tip-link site, which could be as few as one epitope per link. The antigen with which mAb G19 reacts will be referred to as the TLA.

Cryosections from a number of other chick tissues (heart, liver, lung, kidney, gizzard, skeletal muscle, intestine, and eye) were used to examine the tissue distribution of the epitope recognized by mAb G19. Immunoreactivity was detected only in one other tissue, the retina of the eye (Fig. $4 a$ ). In the retina, mAb G19 stains the ciliary calyx (Fig. $4 a$ ), a ring of microvilli that surrounds the outer segment of the photoreceptors. The ciliary calyx is also stained by $\mathrm{mAb} \mathrm{E} 40$, an $\mathrm{mAb}$ that recognizes a component of the ankle links of the hair bundle, the ALA (Goodyear and Richardson, 1999) (Fig. 4b). The ciliary calyx of photoreceptors is, like hair bundles, stained in a distinctly different manner by the antiTLA and anti-ALA mAbs. In photoreceptors, the TLA is distributed along the length of the microvilli comprising the ciliary calyx, whereas the ALA is restricted to the basal region of this structure (Fig. 4a,b). In hair cells, the TLA is concentrated toward the tip of the hair bundle, whereas the ALA is focused around its base (Fig. $4 d, e$ ). mAb D10, an IgG1 mAb of the same isotype as mAbs G19 and E40 that recognizes a component of the shaft connectors of the hair bundle, the HCA, does not label the ciliary calyx of photoreceptors (Fig. $4 c, f$ ).

Utricular maculae were used to assess the sensitivity of the TLA to treatment with either the calcium chelator BAPTA or the protease subtilisin and to compare its sensitivities to these treatments with those of the ALA, which is known to be both BAPTA and subtilisin sensitive (Goodyear and Richardson, 1999). Like the ALA, the TLA is BAPTA sensitive, and the epitope can no longer be detected on the surface of the hair bundle after treatment with $5 \mathrm{~mm}$ BAPTA for $15 \mathrm{~min}$ (Fig. $5 a-d$ ). Unlike the ALA, the TLA is relatively insensitive to subtilisin treatment. The epitope is readily detected after hair bundles have been treated with subtilisin for $15 \mathrm{~min}$ in the presence of the otoconial membrane (Fig. $5 e-h$ ). If the otoconial membrane is removed before subtilisin treatment, there is a decrease, but not a complete loss, in the level of anti-TLA staining associated with the surface of the hair bundle. In contrast, the ALA is extremely sensitive to subtilisin exposure, regardless of the presence (Fig. $5 h$ ) or absence (data not shown) of an otoconial membrane. A recent study has shown that exposing hair cells to $5 \mathrm{~mm}$ lanthanum causes the loss of tip links from hair bundles (Kachar et al., 2000). The TLA, but not the ALA, is sensitive to lanthanum treatment, and the epitope is only barely detectable on the surface of the hair bundle after exposure to $5 \mathrm{~mm}$ lanthanum for $10 \mathrm{~min}$ in the presence of $4 \mathrm{~mm}$ calcium (Fig. 5i-l).

If maculae are treated with subtilisin for a period of $1 \mathrm{hr}$ in the absence of the otoconial membrane, immunoreactivity for $\mathrm{mAb}$ G19 is considerably diminished (Fig. 6a,b). However, tip links (Fig. $6 c, d$ ) and kinocilial links $(e, f)$ can still be readily observed by electron microscopy after such an extended treatment period, indicating that the TLA is more sensitive to proteolysis than the structure with which it is associated. Ultrastructural observations also indicate that kinocilial links, like tip links, are lost when hair 

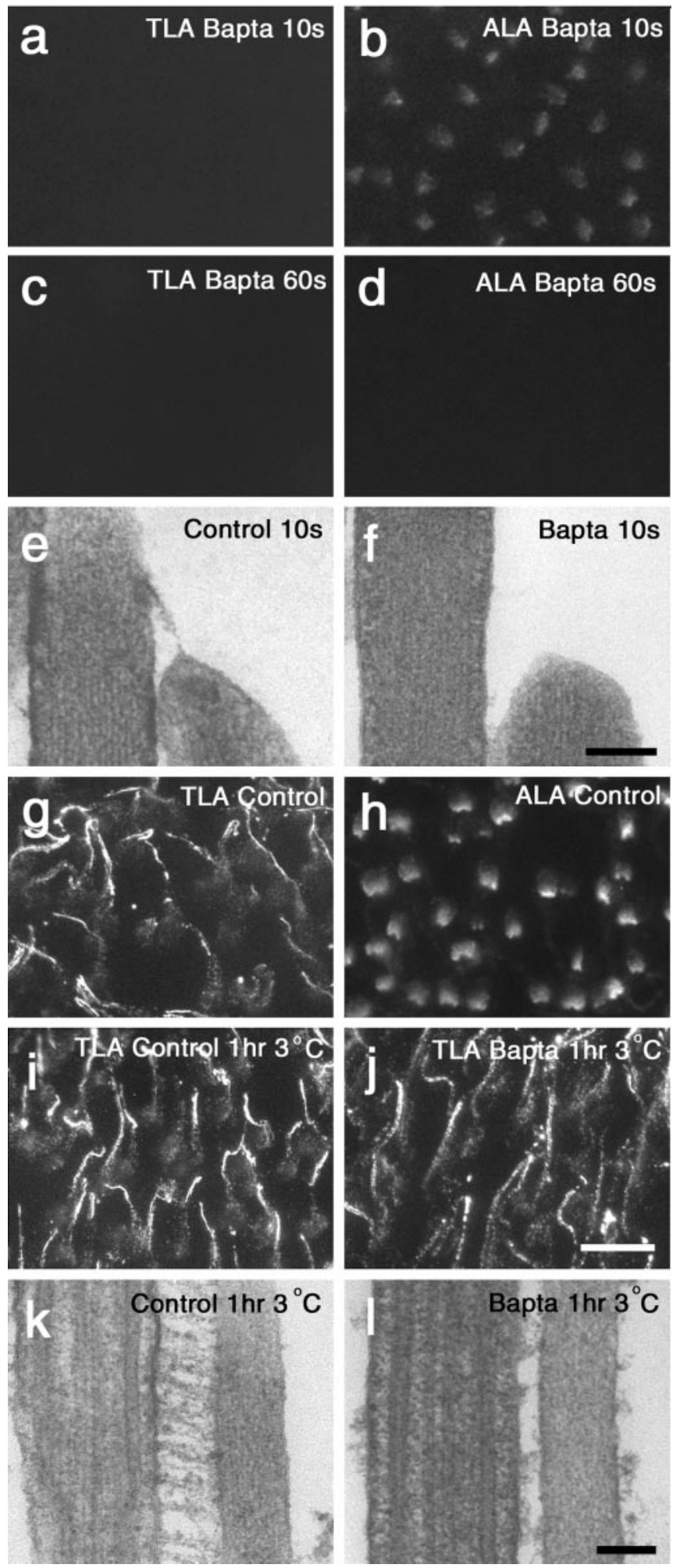

Figure 7. Effects of BAPTA treatment at ambient and low temperatures. Immunofluorescence micrographs of whole mounts $(a-d, g-j)$ and electron micrographs of hair cells $(e, f, k, l)$ from utricular maculae that were dipped in BAPTA $(a-d, f, j, l)$ or saline $(e, g-i, k)$ before fixation and immunostaining for either the $\operatorname{TLA}(a, c, g, i, j)$ or the ALA $(b, d, h)$, or preparation for electron microscopy $(e, f, k, l) \cdot a, b$, BAPTA treatment for 10 sec at room temperature. $c, d$, BAPTA treatment for $60 \mathrm{sec}$ at room temperature. $e$, Saline treatment for $10 \mathrm{sec}$ at room temperature. $f$, BAPTA treatment for $10 \mathrm{sec}$ at room temperature. $g, h$, Saline treatment for $1 \mathrm{hr}$ at room temperature. $i, k$, Saline treatment for $1 \mathrm{hr}$ at $3^{\circ} \mathrm{C} . j, I$, BAPTA treatment for $1 \mathrm{hr}$ at $3^{\circ} \mathrm{C}$. Scale bars: (in j) $a-d, g-j, 10 \mu \mathrm{m}$; (in f) $e, f, 100 \mathrm{~nm}$; (in /) k, l, $100 \mathrm{~nm}$. cells are exposed to $5 \mathrm{~mm}$ BAPTA for $15 \mathrm{~min}$ at room temperature (Fig. 6g,h).

The TLA disappears very rapidly from the surface of the hair bundle in response to BAPTA treatment and is lost more rapidly than the ALA (Fig. $7 a-h$ ). BAPTA exposure times of $10 \mathrm{sec}$ are sufficient to cause complete loss of the G19 epitope from the cell surface, a time point at which the ALA is still readily detectable (Fig. 7a,b). Tip links cannot be observed by electron microscopy on hair cells that have been treated with BAPTA for $10 \mathrm{sec}$ (Fig. $7 e, f)$, nor can kinocilial links (data not shown). The ALA is retained on the cell surface if hair cells are treated with BAPTA at low temperature (Goodyear and Richardson, 1999). Likewise, the TLA is retained on the cell surface when BAPTA treatment is performed at low temperature, even if treatment times are extended to $1 \mathrm{hr}$ (Fig. $7 k, l$ ). However, distinct kinocilial links cannot be observed after a $1 \mathrm{hr}$ period of treatment with BAPTA at low temperature (Fig. $7 k, l$ ), and tip links are not readily detectable (data not shown).

Tip links, ankle links, and the ALA all reappear on the surface of the hair bundle during the course of a 20-24 hr period after exposure to BAPTA at room temperature (Zhao et al., 1996; Goodyear et al., 1999). The TLA also reappears on the surface of the hair bundle after BAPTA treatment at room temperature (Fig. 8). Reappearance of the TLA is rapid, relative to the times reported for tip-link recovery, and substantial immunoreactivity can be observed after a $1 \mathrm{hr}$ in vitro recovery period after BAPTA treatment (Fig. $8 a-h$ ). However, most of the TLA observed at this early time point appears to be associated with the taller stereocilia in the hair bundle, those that lie immediately adjacent to the kinocilium, because in most instances only two fine, closely spaced lines of staining are observed, extending up from the base toward the tip of the stereociliary bundle (Fig. $8 f, f^{\prime}$ ). Little, if any, staining is associated with the tips of the stereocilia within the hair bundle at this recovery time point. At $22 \mathrm{hr}$ after BAPTA treatment, only the distal ends of the taller stereocilia are stained intensely, and labeling is found distributed in a punctiform manner over the entire hair bundle (Fig. 8j,j'). Staining observed with the anti-ALA mAb also recovers to control levels by $22 \mathrm{hr}$ after BAPTA treatment (Fig. $8 k, l$ ).

The TLA is also sensitive to calcium chelation in the retina, as is the retinal form of the ALA (Fig. 9). It has not been determined whether either the TLA or the ALA present in the retina recover after their loss induced by calcium chelation.

During the development of the auditory basilar papilla, the TLA can be first detected at embryonic day 6.5 (E6.5) on hair cells located in the distal, low-frequency end of the organ (Fig. 10a). This corresponds to the time and place at which hair bundles can be first observed in the basilar papilla by scanning electron microscopy (Cotanche and Sulik, 1984) and immunostaining for the HCA (Bartolami et al., 1991; Goodyear and Richardson, 1997). By E9 (Fig. 10b), staining is observed throughout the organ, and the level of staining is intense relative to that observed at later stages when it becomes progressively restricted to the top of the hair bundle $(c, d)$. The TLA is detected on auditory hair bundles in the basilar papilla of adult chickens and resembles that seen in the early posthatch chick (Fig. 10e).

Immunoblotting different fractions prepared from the utricular macula or the retina with mAb G19 failed to identify the TLA (data not shown), indicating that the antibody is most likely to recognize a conformation-dependent epitope or that the antigen is present at a very low copy number and therefore below the detection limits of the techniques used. Experiments in which various retinal fractions were tested for their ability to block G19 
TLA Control
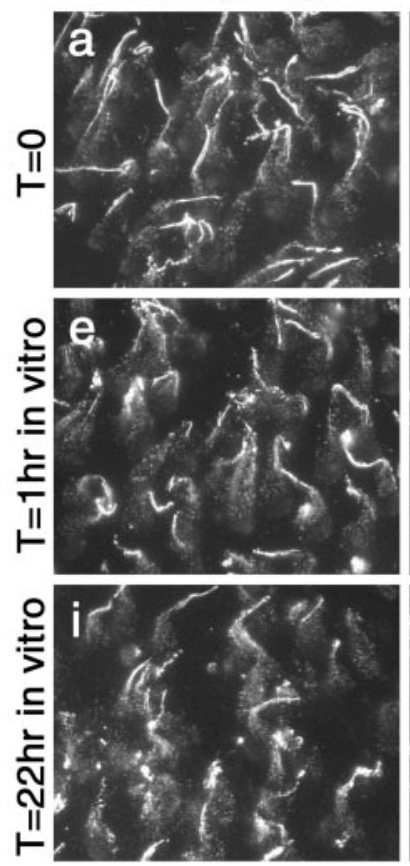

TLA Bapta
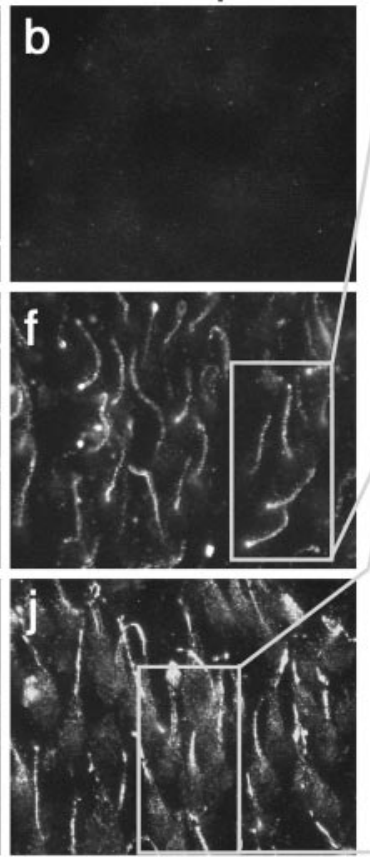

ALA Control
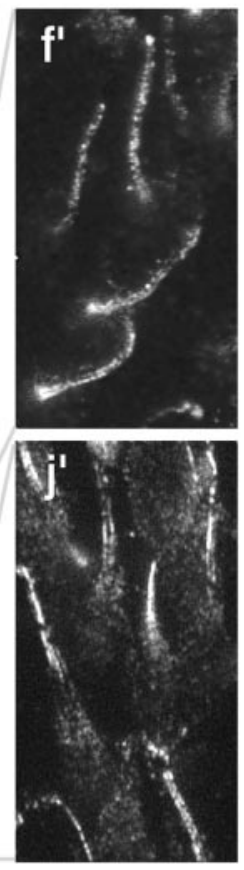
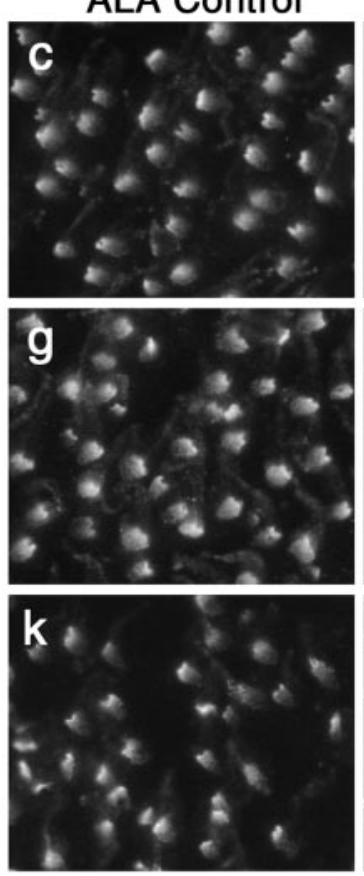

ALA Bapta

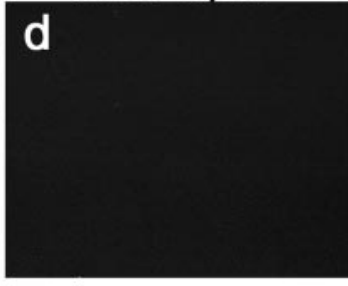

h
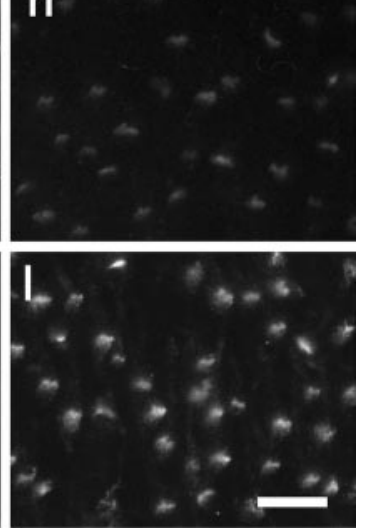

Figure 8. Reappearance of the TLA and the ALA on the surface of the hair bundle after BAPTA treatment. Immunofluorescence micrographs of saline-treated $(a, c, e, g, i, k)$ and BAPTA-treated maculae $\left(b, d, f, f^{\prime}, h, j, j^{\prime}, l\right)$ that were fixed immediately after BAPTA treatment (T = $\left.0 ; a-d\right)$ and at 1 (T $=1 \mathrm{hr}$ in vitro; $\left.e-h\right)$ or 22 (T $=22 \mathrm{hr}$ in vitro; $\left.i-l\right)$ hr in vitro after BAPTA treatment and subsequently stained for the TLA $(a, b, e, f, i, j)$ or the ALA $(c, d, g, h, k, I)$. Both antigens reappear on the hair bundle within $1 \mathrm{hr}$ of BAPTA treatment ( $f, h)$ and can recover to control levels within $22 \mathrm{hr}(j, l)$. Details of the bundles shown in $f$ and $j$ are shown in $f^{\prime}$ and $j^{\prime}$, respectively. Note how the TLA is mostly restricted to the tallest stereocilia at early time points, and that these stereocilia are labeled along their entire length $\left(f^{\prime}\right)$. By $22 \mathrm{hr}$, staining is concentrated at the distal end of the bundles and in puncta at the stereocilia tips ( $\left.j^{\prime}\right)$. T, Time. Scale bar: (in $\left./\right) a-l, 10 \mu \mathrm{m}$.

immunostaining indicated that the TLA was soluble in nonionic detergent, and that the antibody recognized the detergentsolubilized antigen (data not shown). Attempts were therefore made to immunoprecipitate the TLA from retinal extracts prepared in the presence of nonionic detergent. Assuming that the antigen would be a glycosylated cell surface protein, biotinylated concanavalin A and alkaline phosphatase-conjugated streptavidin were used to provide a sensitive system for detecting immunoprecipitated antigens on protein blots. A preliminary screen of tissue sections prepared from the ear and the eye using a panel of biotinylated lectins indicated that concanavalin A stained both hair bundles in the inner ear and the outer-segment region of the retina and was therefore likely to be the most suitable for the detection of the antigens in question. mAb G19 immunoprecipitates two concanavalin A-reactive polypeptides, one that has an electrophoretic mobility similar to that of the laminin light chain and a second that has a mobility slightly greater than that of the skeletal myosin marker (Fig. 11, lane 1). The approximate apparent molecular masses of the bands are estimated to be 250 and 200 $\mathrm{kDa}$, respectively. The anti-ALA mAb F44 immunoprecipitates a concanavalin A-reactive polypeptide that is much larger than either of these two bands, has a mobility that is less than that of the laminin heavy chain, and is estimated to be $\sim 450 \mathrm{kDa}$ (Fig. 11 , lane 3). The 250/200 kDa polypeptides recognized by mAb G19 can be immunoprecipitated from samples that have been treated with EGTA (Fig. 11, lane 5). The $450 \mathrm{kDa}$ polypeptide recognized by mAb F44 cannot be immunoprecipitated in the presence of EGTA (Fig. 11, lane 7).

\section{Discussion}

The results reveal a previously unrecognized similarity between tip links and kinocilial links and identify a second antigen, along with the ALA, that is common to and expressed only by hair cells and photoreceptors. The TLA is the third epitope, together with the ALA (Goodyear and Richardson, 1999) and the HCA (Richardson et al., 1990), to be identified that is specifically associated with the apical membrane of hair cells within the inner ear. The HCA is associated with shaft connectors (Goodyear and Richardson, 1992), the ALA is a component of ankle links (Goodyear and Richardson, 1999), and the TLA is associated with both tip links and kinocilial links.

The distribution of the TLA on the surface of the hair bundle correlates closely with that of tip links and kinocilial links. Furthermore, many of the properties of the TLA are similar to those of tip and kinocilial links. First, tips links are lost from hair bundles after BAPTA treatment (Assad et al., 1991; Goodyear and Richardson, 1999), as are kinocilial links and the TLA. Second, tip-link loss from the surface of the hair cell during BAPTA treatment is very rapid, within $10 \mathrm{sec}$ (Assad et al., 1991), as is loss of the TLA. Third, like the TLA, tip links disappear in response to lanthanum treatment (Kachar et al., 2000). Fourth, the TLA reappears on the hair bundle within $22 \mathrm{hr}$ after BAPTA treatment, as do tip links (Zhao et al., 1996). Although the initial reappearance of the TLA on the surface of utricular hair bundles is fast (within $1 \mathrm{hr}$ ) relative to the time reported for tip-link recovery in the basilar papilla $\left(t_{1 / 2}=8 \mathrm{hr}\right.$ ) (Zhao et al., 1996), this probably reveals the rapid recovery of kinocilial links, because the TLA that reappears within the first hour in vitro is mostly restricted to the tall stereocilia lying adjacent to the kinocilium. Despite these many similarities in the properties of the TLA and tip links, two lines of evidence indicate that mAb G19 recognizes a molecule closely associated with tip links and kinocilial links rather than the protein that forms the filamentous core of these structures. 

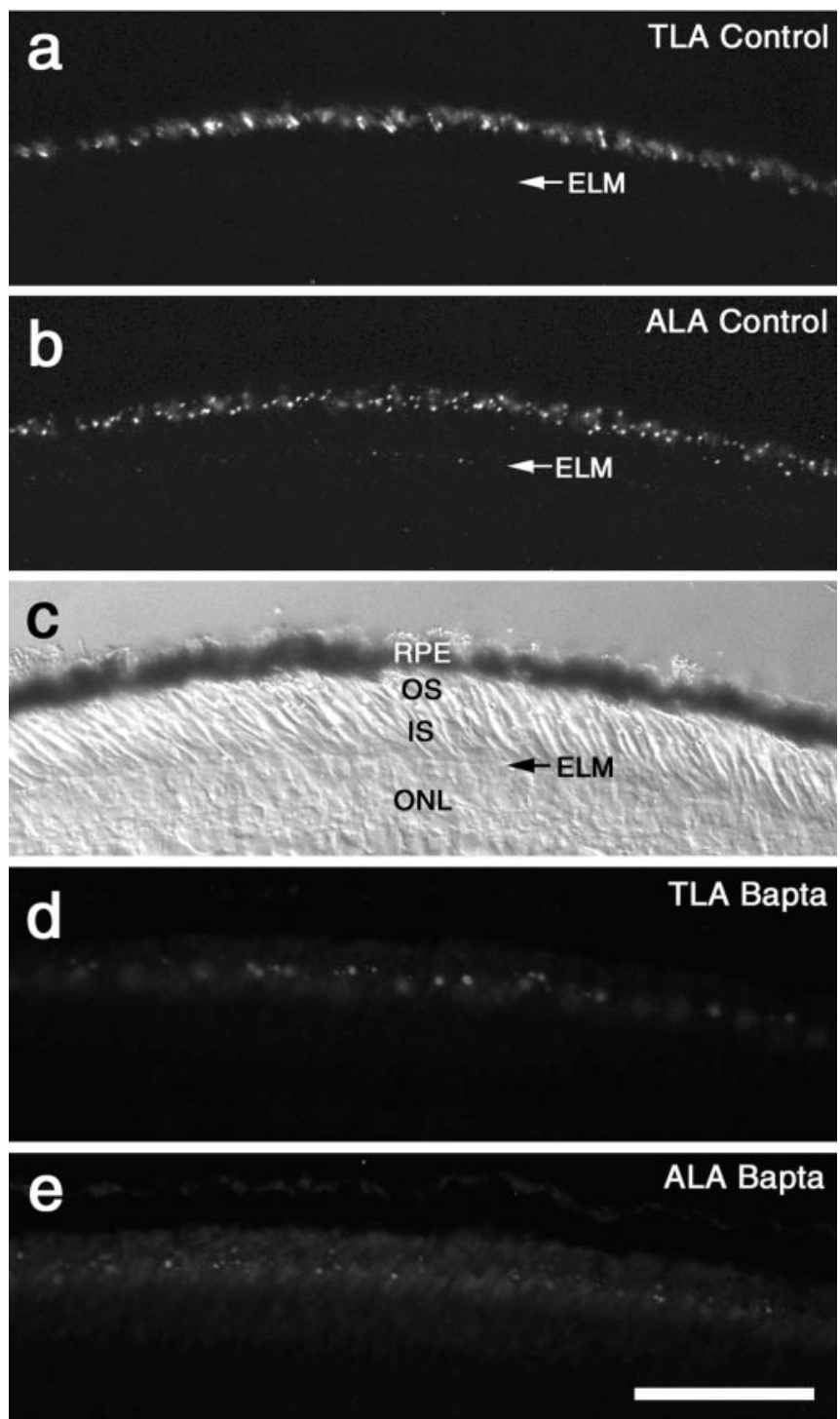

Figure 9. BAPTA sensitivity of the TLA and ALA in the retina. Micrographs of cryosections from control, saline-treated $(a-c)$, and BAPTA-treated retinas $(d, e)$ that have been double-labeled with mAbs of different isotypes for the TLA $(a, d)$ and the ALA $(b, e)$. A phase-contrast image of the section labeled in $a$ and $b$ is shown in $c$. The retinal forms of the TLA and the ALA are both BAPTA sensitive. The residual fluorescence in dand e is from colored oil drops in the cones. RPE, Retinal pigment epithelium; OS, photoreceptor outer segments; IS, photoreceptor inner segments; ELM, external limiting membrane; ONL, outer nuclear layer. Scale bar: (in e) $a-e, 100 \mu \mathrm{m}$.

First, although tip links, top links, and the TLA all withstand short (15 $\mathrm{min}$ ) exposure to subtilisin in the presence of the otoconial membrane, after extended subtilisin treatment ( $1 \mathrm{hr})$ in the absence of the otoconial membrane, the TLA mostly disappears, whereas tip links and kinocilial links remain intact. Second, distinct kinocilial and tip links cannot be detected after BAPTA treatment at low temperature, although the TLA is still present. These observations therefore suggest that the epitope recognized by mAb G19 is located on a protein closely associated with these types of link.

Kinocilial links have been described previously in amphibians (Hillman, 1969; Hillman and Lewis, 1971), reptiles (BaggerSjöbäck and Wersäll, 1973), mammals (Erneston and Smith, 1986), and fishes (Nagel et al., 1991), but the possibility that they are related or similar to tip links has not been considered previously. Both have a similar maximum length $(120-180 \mathrm{~nm})$, and
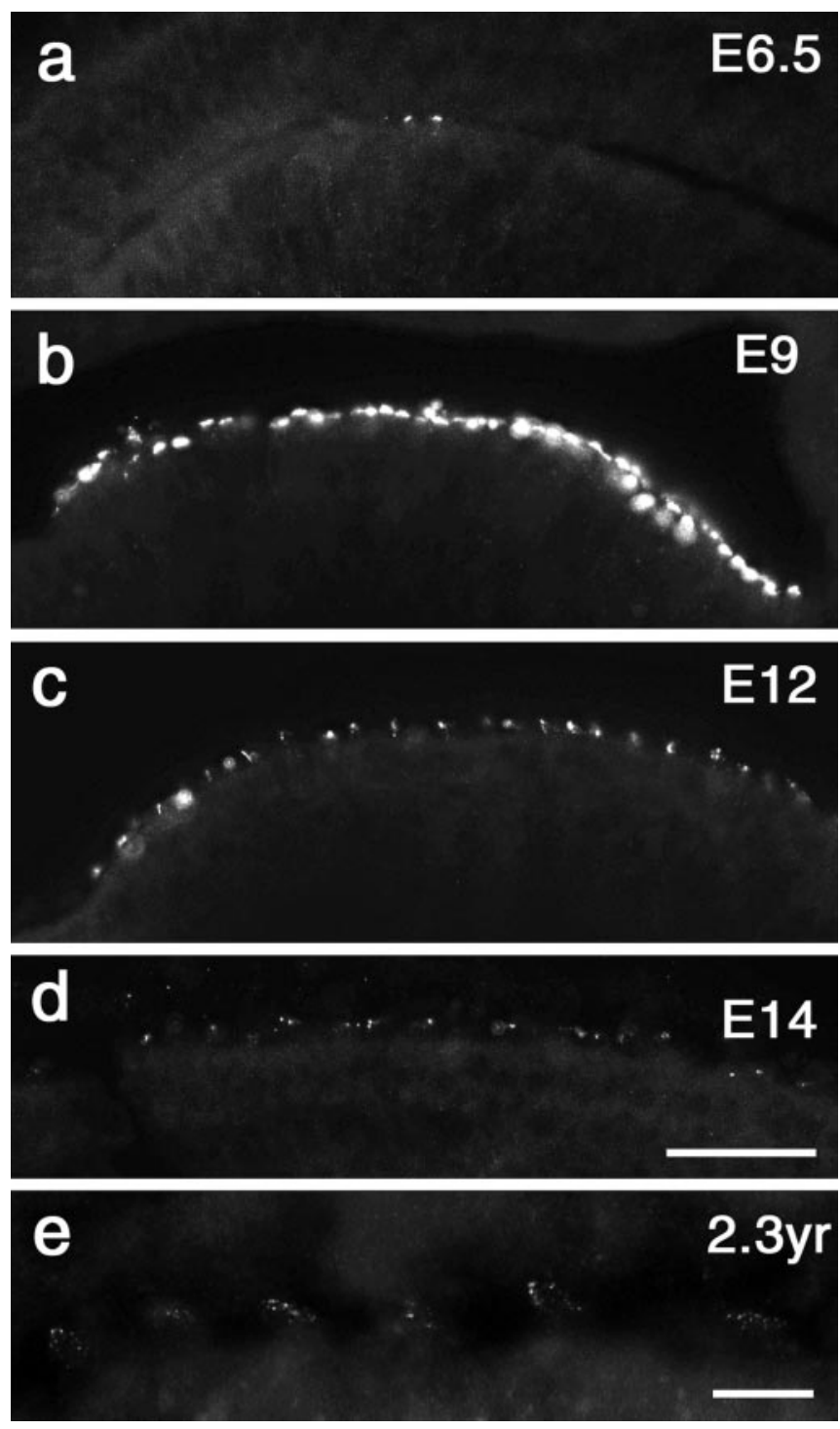

Figure 10. Appearance and distribution of the TLA during development of the basilar papilla. Immunofluorescence micrographs of sections from the basilar papilla at E6.5 (a), E9 (b), $\mathrm{E} 12(c), \mathrm{E} 14(d)$, and 2.3 years of age (e) stained for the TLA with mAb G19. The TLA appears in the distal end of the papilla at E6.5 $(a)$ and is expressed at high levels over the entire surface of each hair bundle by E9 (b). Staining intensity decreases by E12 (c) and is also reduced by E14 (d). The TLA can be detected on papillar hair bundles in mature chickens (e). Scale bars: (in $d$ ) $a-d, 50 \mu \mathrm{m} ; e, 10 \mu \mathrm{m}$.

individual kinocilial links have a diameter similar to that of tip links (4-5 nm). The length of kinocilial links can vary along the extent of a single kinocilium and may depend on the spacing between the kinocilium and adjacent stereocilia. Their exact dimensions may also depend on fixation conditions and the degree of lateral aggregation. Individual kinocilial links may, like tip links (Kachar et al., 2000; Tsuprun and Santi, 2000), actually be formed from thinner, helically wound filaments, and kinocilial links can clearly cluster laterally to form thicker structures (as in Fig. 2d). Osmiophilic submembranous densities at the attachment sites of kinocilial links in the kinocilium have been described previously (Hillman, 1969; Bagger-Sjöbäck and Wersäll, 1973; Erneston and Smith, 1986; Nagel et al., 1991). Although less frequently encountered and less prominent, similar densities are also found at the attachment sites of kinocilial links in the stereocilia. Similar submembranous densities are found at the sites in 


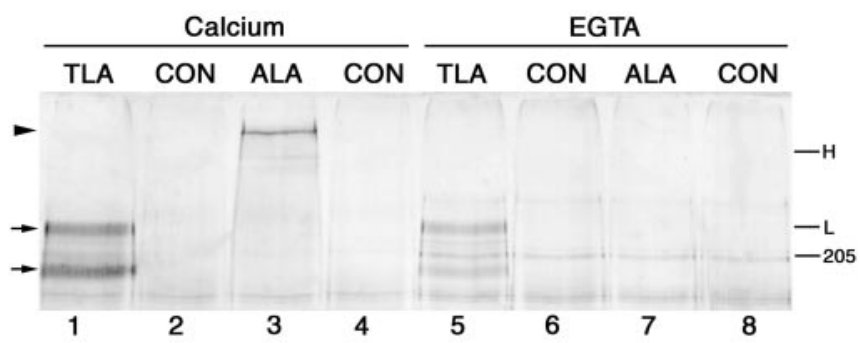

Figure 11. Immunoprecipitation of the TLA and the ALA from retina. Concanavalin A-stained immunoblots of retinal proteins immunoprecipitated with anti-TLA IgG1 mAb (TLA; lanes 1,5), anti-HCA IgG1 control mAb (CON; lanes 2, 6), anti-ALA IgG2a mAb (ALA; lanes 3, 7), and anti-HCA IgG2a control $\mathrm{mAb}(\mathrm{CON}$; lanes 4, 8). The proteins were immunoprecipitated from retinal homogenates that had been incubated in saline containing $1 \mathrm{~mm}$ calcium (lanes 1-4) or saline containing $5 \mathrm{~mm}$ EGTA (lanes 5-8) for $15 \mathrm{~min}$ at room temperature before solubilization with Triton X-100. The anti-TLA mAb immunoprecipitates two polypeptides with apparent masses of 250 and $200 \mathrm{kDa}$ (arrows) in the presence (lane 1) and absence (lane 5) of calcium. The anti-ALA mAb immunoprecipitates a polypeptide with an approximate apparent mass of 450 $\mathrm{kDa}$ (arrowhead) in the presence of calcium (lane 3) but not in the presence of EGTA (lane 7). Markers indicated on the right are laminin heavy chain $(\mathrm{H})$, laminin light chain $(\mathrm{L})$, and skeletal muscle myosin (205).

which the tip links attach to the side of the taller stereocilium (Furness and Hackney, 1985; Osborne et al., 1988; Nagel et al., 1991; Kachar et al., 2000) and may be composed of clusters of myosin 1c motors (Gillespie and Corey, 1997; Garcia et al., 1998; Steyger et al., 1998). The composition of the submembranous densities associated with the kinocilial links within the kinocilium is not known, but myosin 1c is present in the kinocilial bulb of frog saccular hair cells (Hasson et al., 1997; Garcia et al., 1998), a region in which kinocilial links are prominent (Hillman, 1969; Hillman and Lewis, 1971). As shown previously in fish (Rüsch 1985; Neugebauer and Thurm, 1987; Rüsch and Thurm, 1990), kinocilial links in the chick, like tip links (Assad et al., 1991; Goodyear and Richardson, 1999), are sensitive to divalent cation chelation. Furthermore, kinocilial links, like tip links (Jacobs and Hudspeth, 1990; Goodyear and Richardson, 1999), are resistant to subtilisin treatment, even for extended periods. Kinocilial links and tip links therefore share a number of morphological and biochemical properties.

If kinocilial links and tip links are similar proteins, one can ask whether they have the same function. Tip links are thought to gate the mechanotransducer channel (Pickles et al., 1984; Assad et al., 1991), and evidence indicates these channels may lie at each end of the tip link (Denk et al., 1995). The kinocilium is not thought to play a role in transduction. It is lost from auditory hair cells during maturation, and studies in which the kinocilium has been detached from the hair bundle (Hudspeth and Jacobs, 1979) indicate that it is not essential for mechanotransduction. The extent to which kinocilial detachment causes a decrease in the total available transducer conductance is unknown, but the main function of kinocilial links may be to physically couple the kinocilium to the hair bundle.

The types of proteins that form kinocilial links, tip links, and ankle links are not known, but a number of possibilities exist. These include transmembrane proteins with large extracellular domains that interact homophilically or heterophilically and secreted proteins that form links by association with cell surface receptors. Two potential interstereocilial link proteins, cadherin 23 and protocadherin 15, have been described previously (Alagramam et al., 2001a; Di Palma et al., 2001), and mutations in the genes encoding these proteins cause defects in hair bundle devel- opment and deaf blindness in Usher syndrome types 1D and 1F, respectively (Ahmed et al., 2001; Alagramam et al., 2001b; Bolz et al., 2001). The calcium sensitivity of cadherin interactions and the presence of a phenotype in both the ear and eye in Usher type 1 syndrome suggest that the TLA and the ALA may be members of the cadherin superfamily. For classical cadherins, calcium not only stabilizes the structure of the negatively charged cadherin repeat and promotes homophilic interactions between cadherin repeats on adjacent molecules in trans and in cis but also provides protection from proteolysis (Potter et al., 1999; Angst et al., 2001). After BAPTA treatment at room temperature, tip links, kinocilial links, and ankle links are all lost from the cell surface, and no evidence has been found for the presence of dissociated links remaining attached to the opposing membranes. If the various links are cadherins, proteolytic cleavage and release of an extracellular domain in the absence of calcium may explain why the TLA and the ALA disappear after BAPTA treatment at room temperature, a suggestion supported by their resistance to BAPTA treatment at a low temperature. However, the TLA, as identified by immunoprecipitation and blotting with concanavalin A, does not appear to be subject to proteolysis in the presence of EGTA and is therefore more likely to be associated with a receptor and released from the membrane after calcium chelation. Four other observations suggest that the TLA and the ALA are unlikely to be cadherin 23 or protocadherin 15 . First, although the existence of tissue-specific splice variants cannot be excluded, both cadherin 23 and protocadherin 15 are more widely expressed than either antigen (Alagramam et al., 2001a; Di Palma et al., 2001; Murcia and Woychik, 2001). Second, in the mouse ear, cadherin 23 is expressed by both hair cells and nonsensory cells in Reissner's membrane (Wilson et al., 2001). Third, although cadherin 23 is expressed on the hair bundle (Boeda et al., 2002; Siemens et al., 2002), it is expressed only transiently during early development, and it cannot be detected on mature auditory hair bundles (Boeda et al., 2002). Fourth, cadherin 23 is BAPTA insensitive and subtilisin sensitive (our unpublished observations), suggesting that it is unlikely to be a core component of either tip links or ankle links, both of which are BAPTA sensitive (Goodyear and Richardson, 1999).

The high TLA expression levels observed on immature auditory hair bundles in the developing basilar papilla support a previous study showing that tip links develop from an extensive array of links located toward the top of the hair bundle and oriented along all of the possible axes (Pickles et al., 1991). Whether all of these links are associated with mechanotransducer channels remains to be determined. If they are, the total transducer conductance of immature hair cells may be high relative to that of mature hair cells, and the directional sensitivity of a hair cell may be less polarized at early stages than it is in the adult. The high level of TLA observed early in development also suggests that it contributes to the process of hair bundle development.

Additional studies are required to fully evaluate the roles played by the TLA and ALA. The molecular cloning of these antigens or their identification as known genes will be important future steps. As antigens expressed exclusively by hair cells and photoreceptors, these proteins may be the products of the as yet-uncharacterized loci for Usher type 1 syndrome. Although the primary sequences of these antigens remain to be determined, the identification of these antigens reveals important similarities and differences in the properties of the different link types associated with the mechanosensory apparatus of the hair cell. 


\section{References}

Ahmed ZM, Riazuddin S, Bernstein SL, Ahmed Z, Khan S, Griffith AJ, Morell RJ, Friedman TB, Riazuddin S, Wilcox ER (2001) Mutations of the protocadherin gene PCDH15 cause Usher syndrome type 1F. Am J Hum Genet 69:25-34.

Alagramam KN, Murcia CL, Kwon HY, Pawlowski KS, Wright CG, Woychik RP (2001a) The mouse Ames waltzer hearing-loss mutant is caused by mutation of Pcdh15, a novel protocadherin gene. Nat Genet 27:99-102.

Alagramam KN, Yuan H, Kuehn MH, Murcia CL, Wayne S, Srisailpathy CR, Lowry RB, Knaus R, Van Laer L, Bernier FP, Schwartz S, Lee C, Morton CC, Mullins RF, Ramesh A, Van Camp G, Hageman GS, Woychik RP, Smith RHJ (2001b) Mutations in the novel protocadherin PCDH15 cause Usher syndrome type 1F. Hum Mol Genet 10:1709-1718.

Angst BD, Marcozzi C, Magee AI (2001) The cadherin superfamily: diversity in form and function. J Cell Sci 114:629-641.

Assad JA, Shepherd GMG, Corey DP (1991) Tip-link integrity and mechanical transduction in vertebrate hair cells. Neuron 7:987-994.

Bagger-Sjöbäck D, Wersäll J (1973) The sensory hairs and the tectorial membrane of the basilar papilla in the lizard Calotes versicolor. J Neurocytol 2:329-350.

Bartolami S, Goodyear R, Richardson G (1991) Appearance and distribution of the $275 \mathrm{kDa}$ hair-cell antigen during development of the avian inner ear. J Comp Neurol 314:777-788.

Boeda B, El-Amraoui A, Bahloul A, Goodyear R, Daviet L, Blanchard S, Perfettini I, Fath KR, Shorte S, Reiners J, Houdusse A, Legrain P, Wolfrum U, Richardson G, Petit C (2002) Myosin VIIA, harmonin, and cadherin 23, three Usher I gene products that cooperate to shape the sensory hair bundle. EMBO J 21:6689-6699.

Bolz H, von Brederlow B, Ramirez A, Bryda EC, Kutsche K, Nothwang HG, Seeliger M, del C-Salcedo Cabrera M, Vila MC, Molina OP, Gal A, Kubisch C (2001) Mutation of CDH23, encoding a new member of the cadherin gene family, causes Usher syndrome type 1D. Nat Genet 27:108-112.

Cotanche DA, Sulik KK (1984) The development of the stereociliary bundles in the cochlear duct of chick embryos. Brain Res 318:181-193.

Csukas SR, Rosenquist TH, Mulroy MJ (1987) Connections between stereocilia in auditory hair cells of the alligator lizard. Hear Res 30:147-156.

Denk W, Holt JR, Shepherd GMG, Corey DP (1995) Calcium imaging of single stereocilia in hair cells: localization of transduction channels at both ends of tip links. Neuron 15:1311-1321.

Di Palma F, Holme RH, Bryda EC, Balyantseva IA, Pellegrino R, Kachar B, Steel KP, Noben-Trauth K (2001) Mutations in Cdh23, encoding a new type of cadherin, cause stereocilia disorganization in waltzer, the mouse model for Usher syndrome type 1D. Nat Genet 27:103-107.

Erneston S, Smith CA (1986) Stereo-kinociliar bonds in mammalian vestibular organs. Acta Otolaryngol 101:395-402.

Furness DN, Hackney CM (1985) Cross-links between stereocilia in the guinea pig cochlea. Hear Res 18:177-188.

Garcia JA, Yee AG, Gilespie PG, Gorey DP (1998) Localization of myosin-I $\beta$ near both ends of tip links in frog saccular hair cells. J Neurosci 18:8637-8647.

Gillespie PG, Corey DP (1997) Myosin and adaptation by hair cells. Neuron 19:955-958.

Goodyear R, Richardson G (1992) Distribution of the $275 \mathrm{kD}$ hair cell antigen and cell surface specialisations on auditory and vestibular hair bundles in the chicken inner ear. J Comp Neurol 325:243-256.

Goodyear R, Richardson G (1997) Pattern formation in the basilar papilla: evidence for cell rearrangement. J Neurosci 17:6289-6301.

Goodyear R, Richardson G (1999) The ankle-link antigen: an epitope sensitive to calcium chelation associated with the hair-cell surface and the calycal processes of photoreceptors. J Neurosci 19:3761-3772.

Hasson T, Gillespie PG, Garcia JA, MacDonald RB, Zhao Y, Yee AG,
Mooseker MS, Corey DP (1997) Unconventional myosins in inner-ear sensory epithelia. J Cell Biol 137:1287-1307.

Hillman DE (1969) New ultrastructural findings regarding a vestibular ciliary apparatus and its possible functional significance. Brain Res 13:407-412.

Hillman DE, Lewis ER (1971) Morphological basis for a mechanical linkage in otolithic receptor transduction in the frog. Science 174:416-419.

Hudspeth AJ, Jacobs R (1979) Stereocilia mediate transduction in vertebrate hair cells. Proc Natl Acad Sci USA 76:1506-1509.

Jacobs RA, Hudspeth AJ (1990) Ultrastructural correlates of mechanoelectrical transduction in hair cells of the bullfrog's internal ear. Cold Spring Harb Symp Quant Biol 55:547-561.

Kachar B, Parakkal M, Kurc M, Zhao Y, Gillespie PG (2000) High resolution structure of hair-cell tip links. Proc Natl Acad Sci USA 97:13336-13341.

Köhler G, Milstein C (1975) Continuous culture of fused cells secreting antibody of predefined specificity. Nature 256:495-497.

Legan K, Goodyear RJ, Oganesian A, Seifert R, Bowen-Pope D, Richardson GP (2001) The $275 \mathrm{kD}$ hair-cell antigen and the glomerular mesangial cell phosphatase rPTP-GMC1 have an identical distribution on the haircell's apical surface. Assoc Res Otolaryngol Abstr 24:138.

Murcia CL, Woychik RP (2001) Expression of Pcdh15 in the inner ear, nervous system and various epithelia of the developing embryo. Mech Dev 105:163-166.

Nagel G, Neugebauer D-C, Schmidt B, Thurm U (1991) Structures transmitting stimulatory force to the sensory hairs of vestibular ampullae of fishes and frog. Cell Tissue Res 265:567-578.

Neugebauer D-C, Thurm U (1987) Surface charges of the membrane and cell adhesion substances determine the structural integrity of hair bundles from the inner ear of fish. Cell Tissue Res 249:199-207.

Osborne MP, Comis SD, Pickles JO (1988) Further observations on the fine structure of tip links between stereocilia of the guinea pig cochlea. Hear Res 35:99-108.

Pickles JO, Comis SD, Osborne MP (1984) Cross links between stereocilia in the guinea pig organ of Corti and their possible relation to sensory transduction. Hear Res 15:103-112.

Pickles JO, von Perger M, Rouse GW, Brix J (1991) The development of links between stereocilia in hair cells of the chick basilar papilla. Hear Res 54:153-163.

Potter E, Clemens B, Brabant G (1999) The cadherin-catenin system: implications for growth and differentiation of endocrine tissues. Endocr Rev 20:207-239.

Richardson GP, Bartolami S, Russell IJ (1990) Identification of a $275 \mathrm{kDa}$ protein associated with the apical surfaces of sensory hair cells in the avian inner ear. J Cell Biol 110:1055-1066.

Rüsch A (1985) Sensoriche und motorische Aktivität vestibulärer Haarinneszellem in jugenstadium des Aals anguilla anguilla. Diplomarbeit, fachbereich Biologie, Universität Munster.

Rüsch A, Thurm U (1990) Spontaneous and electrically induced movements of ampullary kinocilia and stereovilli. Hear Res 48:247-267.

Siemens J, Kazmierczak P, Reynolds A, Sticker M, Littlewood-Evans A, Muller U (2002) The Usher syndrome proteins cadherin 23 and harmonin form a complex by means of PDZ-domain interactions. Proc Natl Acad Sci USA 99:14946-14951.

Steyger PS, Gillespie PG, Baird RA (1998) Myosin I $\beta$ is located at tip link anchors in vestibular hair bundles. J Neurosci 18:4603-4615.

Tsuprun V, Santi P (2000) Helical structure of hair cell stereocilia tip links in the chinchilla cochlea. J Assoc Res Otolaryngol 1:224-231.

Wilson SM, Householder DB, Coppola V, Tessarollo L, Fritzsch B, Lee EC, Goss D, Carlson GA, Copeland NG, Jenkins NA (2001) Mutations in Cdh 23 cause non-syndromic hearing loss in waltzer mice. Genomics 74:228-233.

Zhao Y, Yamoah EN, Gillespie PG (1996) Regeneration of broken tip links and restoration of mechanical transduction in hair cells. Proc Natl Acad Sci USA 93:15469-15474. 